\title{
Pesquisa estética e realidade nacional na poesia concreta e no poema-práxis
}

\author{
Rafael Campos Quevedo* \\ Universidade Federal do Maranhão \\ São Luís, Brasil \\ Recebido em: 26/03/2019 \\ Aceito em: 31/o7/2019
}

Resumo: Propõe-se uma discussão acerca de alguns pontos do debate teórico envolvendo dois movimentos antagônicos da cena vanguardista brasileira dos anos de 1950-196o (a Poesia Concreta do grupo Noigandrese o Poema-Práxis de Mario Chamie) tendo em vista o problema da conciliação entre experimentação formal e abordagem da realidade nacional.

Palavras-chave: Poesia Concreta. Poema-Práxis. Formalismo. Realidade Nacional.

\begin{abstract}
It is proposed a discussion about some aspects of the theoretical debate regarding two antagonistic movements of the avant-garde scenario in Brazil around the 1950 s and the 1960s (the Noigandres group Concrete Poetry and Mario Chamie's Praxis-Poem), considering the issue of the formal experimentation and the national reality approach conciliation.

Keywords: Concrete Poetry. Praxis-Poem. Formalism. National Reality.
\end{abstract}

Resumen: Se propone una discussion acerca de algunos puntos del debate teórico implicando dos movimiento santagónicos de la escena vanguardista brasileña de los años de 1950-196o (la Poesía Concreta del grupo Noigandres y el Poema-Praxis de Mario Chamie) teniendo en cuenta el problema de la conciliación entre experimentación formal y el abrodaje de la realidad nacional.

Palabras clave: Poesía Concreta. Poema-Paxis. Formalismo. Realidad Nacional. 
Poesia Concreta e o Poema-Práxis representam duas linhas de força efetivamente antagônicas do segundo momento vanguardista em nossa poesia do século XX. Sem desconsiderar o contraponto do Neo-Concretismo a certos pressupostos da Poesia Concreta, assim como os desdobramentos das ideias concretistas promovidas pelo Poema-Processo, não se pode negar que esses dois movimentos, apesar de dissidentes, foram continuadores, por seus desdobramentos e experimentações, do núcleo seminal da Poesia Concreta. Poesia Concreta e Práxis atuaram, portanto, a partir de táticas e posicionamentos divergentes, sobre o mesmo raio de problemas e no interior de uma mesma conjuntura. Ambas originaram-se do diagnóstico da disparidade entre a produção poética brasileira e a situação contemporânea (mesmo que dessem a essa designação sentidos distintos). Ambas partiram da ideia de que a "arrancada" dada pela Semana de 22 havia arrefecido e que a Geração 45 representava um retrocesso poético. Uma e outra apostaram na experimentação e creram no seu valor como forma de inserção no mundo. As diretrizes e estratégias de legitimação e inserção na esfera da arte e no mundo da vida encontram-se desenvolvidas nos vários manifestos e textos críticos que lançaram na época e, igualmente nesse aspecto, ambos são caudatários das práticas das vanguardas históricas:

O que primeiro distingue os movimentos de vanguarda é seu modo particular de intervenção cultural que se configura organicamente na primeira década do século XX. Em 19 de fevereiro de 1909, o italiano Filippo T. Marinetti publica no Le Figaro, de Paris, o "Manifesto Futurista", que instaura modalidade imitada e redefinida por quase todos os demais movimentos de vanguarda. Entre o fazer do hábito (reprodução das sujeições da tradição) e a promessa de uma prática desvinculada das regras, produz-se um intervalo que só pode ser anulado por um gênero fundacional e de ruptura como o manifesto. [...] O manifesto apresenta as condições de experimentação (do que ainda não é) e aspira a destruir-se nesse mundo em que sua lógica já não será possível. Em alguns casos, o manifesto percorre todas as etapas da obra vanguardista, tal como ocorre com o quadro Manifesto Intervencionista, de Carrà, no qual a realização de seus postulados o destrói como discurso lógico ou organizado sintaticamente. Nesse 
sentido, realiza-se o que é próprio do manifesto: ser destruído e integrado na prática (AGUILAR, 2005, p. 34).

Em Etapas da arte contemporânea, diz Ferreira Gullar que "a expressão arte concreta parece ter sido cunhada por Theo Van Doesburg, em 1930" (GULLAR, 1985, p. 207). Por mais contraditório que possa parecer, o intuito era o de definir com maior propriedade o que então se conhecia por arte abstrata. A justificativa baseava-se no argumento de que o termo "abstrato" seria melhor empregado se servisse para nomear a arte figurativa, na medida em que o "concreto" seria o objeto real, enquanto que a representação pictórica seria a "abstração" desse mesmo objeto. Nesse sentido, pintar o cavalo seria partir de um dado concreto (o cavalo "real") e abstrair dessa concretude uma figura ilusória: o cavalo pintado. Na arte não-figurativa, a obra, negando o propósito de "ilusão" e emulação da natureza, voltar-se-ia sobre seus próprios elementos (plano, cor, linha, etc.) e ganharia em concretude, pois ofereceria ao mundo das coisas um objeto outro, de significações imanentes e autônomas, sem que sua realidade estivesse subordinada a uma causa anterior, no caso da arte figurativa, o objeto que ela representa. Só seis anos depois, com Max Bill, segundo Gullar, o termo "concreto" passaria a vincular-se a uma arte relacionada a problemas matemáticos e, com isso, começaria a diferenciar-se da arte abstrata genericamente considerada.

É perfeitamente possível fazermos um paralelo entre a argumentação em torno da acepção original da expressão arte concreta e as ideias desenvolvidas pelos poetas brasileiros do Concretismo. O que há em comum é o propósito de desmistificar a arte e dar-lhe um estatuto de concretude. A ideia é banir da arte, seja ela pictórica ou poética, o seu caráter "ilusório", que, na tradição figurativonaturalista das artes plásticas,consistia em um modo de ver a representação artística como emulação da natureza. Já no âmbito da poesia, as presenças do "mito", do "símbolo", do "discurso sobre", da expressão das emoções e outros aspectos são indícios de uma poesia anticoncreta, uma vez que essa, em

\footnotetext{
1 "A poesia concreta acaba com o símbolo, o mito, com o mistério. o mais lúcido trabalho intelectual para a intuição mais clara. acabar com as alusões" (CAMPOS et al., 1975, p. 42). 
princípio, não trata a palavra em sua "concretude", mas subordina-a à condição de veiculadora de conteúdos, mesmo quando explorando a sua materialidade.

Tal posição representa, a nosso ver, o acirramento racionalizante da tendência geral da arte moderna que Ortega y Gasset chamou de "desumanização da arte”. Para o filósofo espanhol, a "nova arte” europeia do século XX apontava para uma profunda transformação dos seus propósitos estéticos, que se vinha refletindo nas várias modalidades artísticas. O fenômeno da desumanização significa, portanto, a opção da arte moderna em distanciar-se da fidelidade para com os temas e motivos "humanos" e voltar-se sobre seus aspectos eminentemente artísticos, leia-se: seus aspectos mais formais. Isso não significa uma simples tendência ao não figurativo, mas sim ao entendimento de que o valor da obra está na reconfiguração do mundo e não na apresentação fiel de sua realidade. É sobretudo nesse aspecto que a arte (e mais posteriormente a poesia) concreta representa o acirramento do processo de desumanização: no combate que o pensamento estético concretista travou contra tudo quanto lhe parecesse “ilusório". Operando com a perspectiva de uma redução do aspecto simbólico da palavra e um "enxugamento" do texto ao nível do "essencial estético" (BENSE, 1971, p. 157), a Poesia Concreta perseguiu a instauração do "espaço verbivocovisual” como uma facticidade singular no manejo com a palavra poética.

Curiosamente, a ideia de realização estética, para um dos teóricos inspiradores do grupo Noigandres, o alemão MaxBense, pressupõe uma menor quantidade de comunicação, que implica, por sua vez, uma maior quantidade de criação. Isso justifica o porquê de a informação estética da Poesia Concreta ser “mais difícil de perceber e apreender que a da poesia clássica, convencional. Só em raros casos se deixa reconhecer de maneira imediata e intuitiva e tem qualidade sensorial. No mais das vezes, deve ser reexecutada de maneira intelectual, construtiva" (BENSE, 1971, p. 198). Tal pensamento está ligado diretamente aos postulados da teoria da informação, conforme consta no livro de Décio Pignatari Informação linguagem comunicação.

A ideia básica da obra citada é a de que o êxito da comunicação (leia-se: a transmissão da mensagem de um emissor ao destinatário) está diretamente ligado ao grau de redundância da enunciação da mensagem. Por redundância 
devemos entender a quantidade de repetição de elementos já conhecidos (e até mesmo previstos) pelo repertório do intérprete. No entanto, o sucesso da comunicação não implica em alta quantidade de informação. Essa depende diretamente da quantidade de elementos novos (não redundantes) incorporados à mensagem. Assim, "lugares-comuns, por exemplo, são menos esclarecedores do que grandes poemas” (PIGNATARI, 1991, p. 48). O elemento novo representa, também, a possibilidade de combater a "tendência entrópica" do sistema de comunicação, na medida em que contribui para o "alargamento do repertório" e redução da "taxa de redundância" desse mesmo sistema. Entropia significa, aqui, o coeficiente de desordem de um determinado sistema. No caso do sistema de comunicação, quanto maior a entropia menor o êxito da comunicação (entropia negativa $=$ informação) $)^{2}$.

Trazendo tais conceitos para o âmbito da poesia, temos que um poema de fácil compreensão pode ser consequência do alto grau de redundância dos elementos que entraram na sua composição. Um poema que causa resistência à rápida compreensão, por sua vez, indica a presença de elementos novos (ou, pelo menos, pouco redundantes) em sua apresentação. Tal poema é, nessa visão, mais inventivo e, além disso, mais informativo do que o primeiro: "E, realmente, a ideia de 'informação' está ligada, mesmo intuitivamente, à ideia de surpresa, de inesperado, de originalidade. Quanto menos previsível, ou mais rara, uma mensagem, maior sua informação" (PIGNATARI, 1991, p. 48).

Parece lícito supor, a partir dessas considerações, que o leitor de um poema concreto difere do leitor de um poema convencional na medida em que a disposição do segundo, diante da obra, é uma disposição de "transcendência", ao passo que o primeiro trava, com a obra, uma relação de "imanência”. O grau de transcendência de um poema não-concreto seria dado pelo fato de o texto suscitar um “para-além” de si mesmo. A imagem poética, por exemplo, é um para-além da palavra em sua facticidade (os seus sinais gráficos impressos no

\footnotetext{
${ }^{2} \mathrm{~A}$ quantidade de ruído de um canal, por exemplo, tende a aumentar o grau de entropia. Isso gera um desejo de maior redundância por parte do emissor, como mostra o seguinte exemplo de Gullar: "Ex.: se a mensagem a transmitir é 'eu te amo', os ruídos e interferências poderiam levar o receptor a entender 'não te amo'; essa possibilidade seria menor se eu acrescentasse à mensagem uma reiteração: 'eu te amo, meu amor'” (GULLAR, 2002, p. 204).
} 
papel) e isso implica, de fato, em considerar esse poema como discurso sobre o mundo, experiência existencial, etc. Já no poema concreto a "leitura" seria, em princípio, a constatação de uma estrutura dada. As significações devem ser buscadas nas relações dos signos entre si em estratégias de visualidade e/ou estruturação sonora, o que não significa o absoluto divórcio com o mundo, sem o qual as palavras no papel não passariam de tracejados desconexos e ininteligíveis. O leitor, no entanto, não deve buscar compreender esse parentesco pela via de uma interpretação metafórica, pelo menos assim o pretende o poema concreto ao propor interditar essa possibilidade na própria constituição do poema. Dessa forma, a relação objeto e signo, ainda segundo a terminologia peirceana adotada por Bense, é uma relação "primacialmente indicial” (ou seja, trabalha com as palavras enquanto índices).

Dentre as várias críticas de Chamie à Poesia Concreta encontra-se uma que diz respeito diretamente à questão do poema como objeto. Iremos tomá-la como ponto de partida para este momento de apresentação dos pressupostos teóricos da vanguarda Práxis:

c) firmaram pé [os concretistas] em que um poema "não é intérprete de objetos exteriores". Ora, se não é intérprete de objetos do mundo exterior, só pode ser intérprete de si mesmo. Para tanto teria que eliminar todas as conotações possíveis com o que está fora dele, inclusive com o leitor que não vê nem lê, jamais, sem um mínimo suficiente de interpretação. Acontece que as palavras, por si só, já são um significado interpretado e não existe em semiótica (teoria da informação ou linguística) nada que seja denotação pura (CHAMIE, 1974b, p. 36).

Esse tipo de crítica à Poesia Concreta perpassa boa parte dos textos dos dois volumes que compõem a Instauração Práxis, assim como aparece, de forma mais ou menos recorrente, em outros textos teóricos de Mário Chamie. O cerne da diferença de posicionamento está em que, para Chamie, a Poesia Concreta 
votou todos os seus esforços para desligar as conexões entre poesia e mundo, o que desembocaria em uma nova modalidade de formalismo estético. O que colocaria a Práxis na posição de antípoda desse pensamento seria, justamente, a tentativa de fundar uma poesia totalmente comprometida com o mundo, ou seja, uma poesia de "levantamento".

A ideia de levantamento é muito cara aos primeiros escritos de Chamie e é a principal arma de combate contra o que o poeta julgou tratar-se de momentos formalistas da poesia brasileira, representados pela geração de 45 e pelo movimento da Poesia Concreta. O formalismo típico desse último seria uma consequência direta da tentativa de eliminação da palavra como "expressão" e "representação" do mundo prescrita pela teoria da Poesia Concreta e que orientaria a experimentação do grupo. Por sua vez, a precedência da teoria como receituário para a produção poética já seria, segundo Chamie, mais um indício de formalismo, na medida em que o poema seria uma "ilustração" da teoria e não uma poesia interessada na abordagem da realidade mundana.

Nesse sentido, a poesia como levantamento significaria, para Chamie, a contrapartida de um formalismo estético, sobretudo porque partiria da experiência com uma determinada realidade (a área de levantamento), reorganizando-a no corpo do poema. Por causa disso, nenhuma teoria viria predeterminar a feição de um poema práxis, no máximo funcionando como reflexão segunda, ou até mesmo terceira, uma vez que o próprio texto poético já seria uma reflexão (e não reflexo, como quis Chamie) da realidade.

Embora a teoria de Chamie aborde questões referentes ao âmbito formal como "espaço empreto", "geometrismo móvel", etc., estas não representam a preocupação central das suas reflexões. Elas aparecem como agentes que possibilitariam aquilo que, a nosso ver, é o escopo último da Práxis, a saber, a consecução do poema de amplitude coletiva, seja no ponto que toma como partida (o levantamento de uma área que já pressupõe uma comunidade de agentes envolvidos), seja no ponto de chegada: o ato de consumir (identificação de uma coletividade com o texto poético que diz respeito à sua realidade, e a abertura para a intervenção dos leitores na reorganização dos elementos do poema, possibilitando novas construções de sentido). 
Em várias passagens do seu corpus ensaístico, Chamie fala sobre o processo que o levou à composição de Lavra lavra (1962), livro que estreia a Práxis como poética de vanguarda. Chamie define tal processo como um autêntico "trabalho em campo" (CHAMIE, 1974b, p. 51). No caso, o autor faz referência aos dez meses que passou em Severínia, interior de São Paulo, lugar escolhido para o processo de imersão na realidade do homem do campo (o lavrador), objeto de problematização do livro em questão. A citação seguinte mostra os elementos "levantados" durante esse período:

Conhecemos seu vocabulário [do lavrador], seus cacoetes, sua dicção, seu cotidiano de sol a sol, sua carência moral, física e ideológica, seu misticismo rudimentar, suas frustrações, sua situação perante os donos da terra, sua fome, sua convivência com a morte e a doença, sua desproteção e fragilidade, sua imagem anti-urbana e o desprezo político e econômico que o vitima. Estivemos com ele em todos os momentos e passos de seu trajeto circular: desde o instante em que revolve a terra, lança a semente, planta, até aquele em que faz a colheita e retira seus proventos do armazém, sem dinheiro para saldar débitos acumulados. Seguimos o ciclo telúrico do lavrador e anotamos tudo o que revelasse o seu dramático tipo antropológico. O livro Lavra Lavra é o repertório móvel e a estrutura, em nível de solução estética, desse levantamento direto (CHAMIE, 1974b, p. 51).

Este é, de forma exemplificada, o processo de captura daquilo que Chamie designou como "estrutura genética" da realidade. O poeta vem a impregnar-se pela lógica e pela dinâmica que rege a vida do homem do campo (no caso de Lavra lavra) e deixa-se "entrosar com a situação", ora agindo sobre ela, ora recebendo a ação que vem dela:

\footnotetext{
Uma vez, somos nós que nos entrosamos com a situação do homem do campo; outra vez, somos entrosados nela; e desse jogo dialético saímos comprometidos com o nosso próprio sistema válido de participação. Só com essa repetição mútua de entrosamento é que um poeta, fora da situação do homem do campo, pode falar desse homem e só, assim, pode esse homem aceitar e se ver, ao nível de sua consciência, naquilo que dele o poeta diz (CHAMIE, 1974a, p. 30).
}

O poema será sempre, portanto, um resultado desse entrosamento do poeta com a área de levantamento, ao passo que ao processo que constitui a transposição das estruturas da realidade para a estrutura do poema, Chamie 
denominou "virtualização"3. Nesse sentido, a estruturação formal do poema não está previamente estabelecida, mas depende de como a área em questão irá "ditar" suas especificidades constitutivas e de como o poeta estará sensível à virtualização destas na configuração espacial do poema.

Em decorrência disso, a mobilidade interna dos textos de Lavra lavra possui a mesma característica cíclica do "trajeto circular" da existência do lavrador. Certo aspecto da fala campesina é refletido no poema por meio de uma dicção truncada, como mostra a disposição das palavras no poema "Plantio". A lógica da explorarão do trabalho é problematizada não só tematicamente, ao longo dos textos, mas aparece, sobretudo, "dramatizada" sob a forma do desempenho das próprias palavras no interior do texto, como mostra o poema "Compra e venda":

\author{
De mão a mão \\ passa o produto passa. \\ A boca fecha. \\ De não e não o punho fecha. \\ Moeda passa para o negócio passa. \\ O tributo de sol a sol e a mão ao pão espera. \\ A boca abre: \\ passa o produto e a tarde. \\ Mira mira \\ corre o dinheiro corre. \\ O bolso rega. \\ De trem a trem o trilho reza. \\ A féria corre para o balanço corre. \\ O meeiro de sol a sol e a mão ao pão estorque. \\ O bolso seca: \\ corre o dinheiro à meca. \\ De dia a dia \\ Pesa a proposta pesa. \\ $\mathrm{O}$ faro sente. \\ De mês a mês o lucro mente. \\ A venda pesa para o colono pesa. \\ A carroça de sol a sol e mão ao pão esgueira. \\ O faro falha: \\ pesa a proposta e a palha. \\ De grão em grão \\ pleno é o celeiro pleno. \\ $\mathrm{O}$ jogo pende.
}

\footnotetext{
3 "Que é virtualizar? É dar realidade autônoma, no tempo e no espaço, aos dados do nosso conhecimento. Se a literatura pretende ser forma de conhecimento, ela só o será na medida em que virtualize. Diremos: a literatura é forma de conhecimento com sua categoria própria. Ao contrário do conhecimento filosófico, ela não prima pelo conceitual. É, antes, virtual" (CHAMIE, 1974a, p. 69).
} 


\section{De pio a pio o bico plange. \\ A perda ganha para o consumo ganha. \\ $\mathrm{O}$ roceiro de sol a sol e a mão ao pão esconde. \\ $\mathrm{O}$ jogo finda: \\ Pleno é o celeiro e a finta (CHAMIE, 1978, p. 70).}

Em suma, a exemplificação dessa interdependência entre a estrutura da área de levantamento e a estrutura do poema não quer dizer outra coisa senão que para "literatura-práxis o conhecimento é a projeção da estrutura da realidade através da obra que é sempre um resultado" (CHAMIE, 1974a, p. 70). Com esse argumento Mário Chamie se munia para desfechar contra a Poesia Concreta as acusações de formalismo, uma vez que a estrutura, para os poetas concretos, seria o resultado da manipulação do material linguístico e não da reflexão sobre o mundo. Fica aberto, aqui, o fosso que separa duas orientações distintas sobre poesia: uma que assevera que o significado de um poema está nele mesmo e não em algum contato com a realidade alhures; outra que, por sua vez, coloca a palavra poética na perspectiva de "mediação da energia internados acontecimentos, dos problemas que elas [as palavras] levantam” (CHAMIE, 1974a, p. 172), ou ainda define o poema como "organismo vivo que incorpora e exprime realidades externas a ele, transfigurando-as" (CHAMIE, 2004, p. 280).

Desse modo, Chamie declara posição contrária à perspectiva de abordagem “temática” da literatura: “o ‘tema' da vida do campo, o 'tema' da usura e da exploração capitalista, o 'tema' da revolução cubana, o 'tema' da renúncia de um presidente" (CHAMIE, 1974a, p. 72). Para ele, o fazer poético que se coloca no âmbito da abordagem de temas permanece alheio à situação real e confina-se em um tipo de resultado que só ratifica o hiato que separa os verdadeiros problemas da realidade brasileira e o universo alienado da "Literatura-literária4".

Em se tratando de "poesia de levantamento", portanto, tudo se passa como se sua realização dependesse da transfusão, sem perda, da "energia vital" das coisas para o universo do poema. Como as coisas não são palavras, o máximo que se pode esperar desse procedimento é uma "tradução", isto é, um complicado

\footnotetext{
${ }^{4}$ Esse [o conceito de Literatura-literária] se refere à literatura que não se desvincula de um universo literário estrito, ou seja, uma literatura que, ao invés de partir de uma realidade contextual situada para formular o seu projeto estético revolucionário, prefere retomar, embora pelo reverso, os preceitos de escolas e movimentos anteriores, dando-lhes continuidade histórica (CHAMIE, 1974b, p. 42).
} 
processo de transporte de um sistema de códigos para outro, o que implica em um jogo de perdas e ganhos. Ainda que essa explicação possa se aplicar a outros processos de criação como o do pintor como também o do cientista que se esforça em "decodificar" a natureza, a diferença que Chamie parece querer efetuar de um modo mais incisivo com relação a esses exemplos é a de que a ideia de levantamento envolve a "problematização" no lugar da mera "expressão".

O leque de abrangência do conceito de área de levantamento, todavia, é bastante amplo. É curioso constatarmos a presença do tópico "emoção lírica” no rol dos exemplos apresentados por Chamie. Isso prova que a proposta de levantamento é menos a de um rigoroso "trabalho de campo", tal como foi realizado em Lavra lavra, do que a de uma outra disposição do poeta para com o seu objeto marcada, primeiramente, por uma postura antiexpressiva e mais crítica e, segundo, pela preocupação de evidenciar os nexos do seu objeto com um universo de relações mais amplo, de maneira que o poema informe as ligações, muitas vezes insuspeitas, que regem a própria dinâmica da realidade. Em uma entrevista ao Suplemento Literário de O estado de São Paulo (1966), incluída em Instauração Práxis I, Chamie dispõe-se a exemplificar o processo de criação de um poema práxis e mostra, no ato mesmo da entrevista, os passos dessa realização. Inicia por estabelecer uma área que, na ocasião, foi o computador. A passagem é um pouco longa, mas achamos interessante reproduzi-la, ainda que suprimindo algumas partes, devido ao valor da minuciosidade e da riqueza de detalhes explicativos do mecanismo de composição amparado pelo processo de levantamento:

[...] Suponha, Altmann, que eu queira elaborar um poema sobre um computador. O que faço antes de tudo? Procuro levantar o vocabulário que o identifica e lhe confere realidade dentro do seu contexto. Com o perdão do improviso, digamos que o vocabulário seja este: "computador", "ciência", "eletrônico", "técnica", "cálculo", "precisão", "cibernética", "estatística","equação", "ficha” e "empresa”. [...] Se eu fosse um autor tradicional (de vanguarda ou não), eu poderia projetar meus sentimentos sobre cada uma delas ou simplesmente relacioná-las, adaptando-as e dispondo-as dentro de um esquema formal, préestatuído. Como autor práxis, porém, meu comportamento criativo é outro; vou inter-relacioná-las, colocá-las uma frente a outra, examinar as contradições internas que cada uma carrega consigo. Desse modo (e tendo em vista que sintaxe é o estudo das relações entre os signos) vou proceder a um levantamento de uma sintaxe possível (não 
condicionada por nenhuma regra linguística predeterminada) que o próprio vocabulário registrado contém em si. Suponhamos, então, que eu coloque, de início, frente a frente essas três palavras ou signos: "precisão", "técnica" e "empresa”. Inter-relacionando uma com as outras eu posso obter a seguinte conexão de signos: "A PRECISÃO DA TÉCNICA NAEMPRESA". Suponha, agora, que eu coloque frente a frente estas outras três: "equação", "cibernética" e "ficha". Posso obter essa conexão: "AEQUAÇÃO CIBERNÉTICA DA FICHA". Farei a mesma coisa com mais estas três: "cômputo", "eletrônico" e "ciência". O resultado poderá ser este: "O CÔMPUTO ELETRÔNICO DA CIÊNCIA". Finalmente me sobram duas palavras: "computador" e "estatística". Além de colocar uma diante da outra, digamos que eu queira examinar a contradição interna de uma delas. Escolho para isso a palavra "computador" e vejo que este signo contém dois outros muito conflitantes. Trata-se de "cômputo" e "dor". Organizo, finalmente, esta unidade de composição: "O CÔMPUTO DA DOR ESTATÍSTICA”. [...]

$\mathrm{O}$ autor práxis, porém, não vai apenas do vocabulário à sintaxe. Para entrosar-se criticamente com a dialética interna da área e acionar os seus fatores de transformação, ele põe em prática a relação dos signos (levantados e articulados numa sintaxe) com o contexto geral em que a área se situa. Voltemos ao "computador". Qual o contexto geral em ele se situa? Ainda na base do improviso, eu diria: o contexto que certos problemas de uma civilização tecnológica cria para nós que vivemos o conflito subdesenvolvimento x desenvolvimento. Que problemas? Por exemplo: o da automação e o da mão-de-obra, o da racionalização da produção e do consumo, o do capital e do trabalho, o da organização empresarial num país cujo povo tem ainda um baixo índice sócioeconômico, o do desnível entre uma alta técnica industrial de produção de bens e o pequeno poder de compra e ingresso nesses bens por parte da grande massa, o da emocionalidade e das dolorosas frustrações individuais e coletivas que esse desnível provoca, o do estímulo a uma consciência ideológica e transformadora, etc. São esses problemas que, em última análise, darão sentido ao texto feito sobre o "computador"; São eles que me levam ao levantamento de uma semântica em que, necessariamente, implicam os signos de conexão organizados em sua sintaxe. Bastaria eu estabelecer uma justaposição entre o "cômputo da dor" (que pode ser a soma emocional de tantas frustrações) e a "precisão da técnica na empresa", para eu caracterizar a relação entre os signos (palavras) e o significado contextual da área a que eles se referem. A unidade "cômputo da dor" por si só conflita com a "precisão técnica da empresa" e exterioriza uma semântica proposta pela própria área e não por uma projeção subjetivista do autor (CHAMIE, 1974a, p. 247-249).

\section{Dessa forma, ratificamos o caráter do Poema-Práxis: poema como objeto}

de conhecimento e virtualização de uma problemática. Em um contexto mais amplo: poema que se quis coletivo, porque partia de uma área que por si só era uma dimensão da coletividade e abria-se à intervenção do leitor. 
Do que foi exposto é possível perceber que ambos os projetos tinham em vista um caminho de "revitalização" da palavra poética. Quando a Poesia Concreta abole o verso e libera o signo verbal da cadeia da sintaxe discursiva, a intenção é a de promover a possibilidade de uma manifestação integral das potencialidades verbais, sonoras e visuais da palavra.

Quando a Práxis critica a estrutura do poema concreto é por entender que a palavra verdadeiramente viva é aquela que se abastece na fonte da energia das coisas. Desse modo, o que coloca as duas vanguardas em situação de extremo antagonismo é, nesse aspecto, a ideia de correalidade adotada pela Poesia Concreta contra a relação de interdependência do Poema Práxis com a área de levantamento.

O pressuposto da correalidade promove, inevitavelmente, uma relação de paralelismo entre a palavra e o mundo, ao passo que, por outro lado, se empenha em demarcar os contornos de uma certa noção de autonomia do objeto artístico, autonomia essa que visa garantir as significações da obra poética dentro das suas próprias fronteiras estruturais e não em associações metafóricas e conotativas com os objetos reais.

A Práxis, por sua vez, crê na viabilidade da poesia como discurso sobre o mundo, não pela expressão subjetiva do autor sobre uma determinada temática, mas através da mediação, por parte dele, entre o mundo da experiência e o mundo da expressão artística. Nesse sentido, também atenta (tal como a Poesia Concreta) contra, digamos, a palavra mistificadora e a metáfora como adorno. Só não adota como procedimento viável o desligamento do conteúdo semântico em relação ao mundo, porque, para Chamie, é um elemento indispensável o nexo da palavra com a realidade. O poema, nesse caso, não comunica apenas a si mesmo, mas enfeixa em sua estrutura significados que problematizam um campo de atuação e um conjunto de relações que esse campo suscita.

Entre as duas tendências há uma bifurcação operacional: a primeira pauta suas experimentações no sentido de aproximar-se ao máximo de uma proposta de poema em que o estrato semântico não ocupe o primeiro plano (dividindo a sua 
importância, ao contrário, com a dimensão antidiscursiva e com a espacialidade tipográfica). A outra mantém o semântico na ordem das suas prioridades, por ser parte estrutural da composição da área de levantamento.

Isso posto, seria oportuno discutir, ainda que de forma muito mais breve do que mereceria a questão, o problema da relevância das propostas aqui abordadas para o âmbito da "realidade nacional", o que poderia ser feito por duas vias que se interceptam. A primeira indagaria sobre a contribuição (ou sobre a sua ausência) das vanguardas concretista e práxis para o aprofundamento das questões relacionadas à busca de uma, se não identidade, pelo menos autoimagem da cultura nacional. A outra seria buscar o lugar de contribuição da Poesia Concreta e da Práxis aos problemas levantados pelo Modernismo brasileiro. Como esse representou, principalmente com as primeiras vanguardas dos anos de 1920, um instante de redimensionamento do problema do nacionalismo literário, fica clara, portanto, a ligação entre os dois ângulos do problema. A esse respeito interessa-nos, especialmente, as seguintes indagações: as diferenças de tratamento da dimensão do conteúdo, que, como vimos, separa Poesia Concreta e Práxis, podem funcionar como critério de valor para a aferição da pertinência, ou não, dessas vanguardas para o problema da realidade brasileira? Ou ainda: seriam essas vanguardas, e em especial a Poesia Concreta, um formalismo e, em caso afirmativo, até que ponto é válida uma atitude formalista para a poesia brasileira?

Ao levantarmos tais perguntas tocamos no cerne do problema central do ensaio de Ferreira Gullar de 1969 intitulado Vanguarda e subdesenvolvimento, texto que tem como finalidade básica invalidar as experiências de vanguarda no Brasil. Através de uma ótica materialista-dialética que tenta demonstrar que a experimentação vanguardista descamba para um formalismo abstrato e paralisador, Gullar atribui às vanguardas brasileiras dos anos 1950 e 1960 (aqui, leia-se: Concretismo e Neo-Concretismo), a responsabilidade pelo desencaminhamento da discussão da literatura brasileira sobre as questões de interesse nacional. Sob a linha de pensamento adotada pelo escritor, parece legítima a alegação de Gullar de que o Concretismo representou uma inflexão na história da literatura brasileira, se a encararmos de acordo com a perspectiva de 
uma sucessão de movimentos e obras que, cada qual a seu modo, apresentaram instantes de imersão na busca de uma representação da cultura nacional. Assim, desde o Indianismo, que representou a "busca de uma temática própria para a literatura brasileira" (GULLAR, 2002, p. 186), a nossa literatura persegue a configuração de uma expressão autônoma de um nacionalismo que:

[...] nasceu sob a dominação portuguesa para se concentrar no patriotismo bilaquiano e no ufanismo. Mais tarde, com o Modernismo, manifesta-se uma nova forma de nacionalismo, uma espécie de descoberta e aceitação do país "tal como é". [...] O romance nordestino é um passo adiante nessa redescoberta da realidade brasileira que, de José Américo a Graciliano Ramos, passando por José Lins do Rego e Jorge Amado, atinge a maturidade da visão realista (GULLAR, 2002, p. 232).

A partir dessas considerações, convém explicitar alguns pressupostos básicos que servirão para delimitar os pontos de vista do autor de Poema sujo que nossa argumentação poderá aproveitar como válidos, como também distanciar-se deles em alguns aspectos. Primeiramente, vale relembrar, o pensamento de Gullar, no ensaio em questão, está totalmente assentado sobre certas bases materialistas que podem ser sintetizadas pela premissa de que a "arte - como a ciência, como o pensamento ligado à vida cotidiana - é um reflexo da realidade objetiva" (LUCKACS, apud GULLAR, 2002, p. 221). Sem entrarmos no mérito da validade da opção metodológica do autor, o fato é que, enquanto um olhar possível sobre o problema das vanguardas, a questão suscitada sobre serem essas um problema alheio ao meio cultural brasileiro parece convidativa ao debate, ainda que as soluções a que porventura chegaremos possam tomar rumos opostos aos trilhados pelo poeta e crítico maranhense. Outro ponto, a nosso ver, de extrema importância a ser considerado, diz respeito ao absoluto silêncio de Gullar sobre a existência do Poema Práxis entre as manifestações brasileiras de vanguarda. Esse ponto é de fundamental importância se pensarmos que a inclusão da Práxis no quadro em questão poderia inviabilizar alinha de raciocínio que generaliza as vanguardas da época sob a categoria de formalistas. Ora, se o que sustenta tal classificação é, preponderantemente, a suposta desocupação do concretismo e suas ramificações quanto à abordagem da realidade, em que lugar 
estaria situada a Práxis senão como a contrapartida estética desses movimentos? Ficamos sem explicação para tal negligência, uma vez que não podemos considerar que, na altura em que Gullar publica seu ensaio (1969), ele não tivesse travado contato com as ideias de Mário Chamie. Tal hipótese é improvável devido à proximidade de Gullar (ele mesmo redator do Suplemento Dominical do Jornal do Brasil) com as publicações e os debates que se colocavam na ordem do dia sobre os problemas da poesia.

Delimitando, portanto, os contornos do problema, poderíamos perguntar: será forçoso concordarmos com Gullar quanto ao ponto de vista de que a Poesia Concreta, e, por nossa conta, o Poema Práxis, caracterizam-se como propostas poéticas de índole formalista?

Parece não restar dúvida, a partir do que foi colocado, quanto a um fato comum à Poesia Concreta e à Práxis: ambas trouxeram a discussão sobre a estrutura do poema para o centro do debate teórico sobre poesia. As teorizações a respeito de questões de estrutura como: o espaço em branco (concretista) e o espaço em preto (praxista), a validade ou invalidade do verso, a relação de proximidade e semelhança (a parataxe concretista) contra a dialética interna das palavras (ou o geometrismo móvel da Práxis), bem como uma série de outros assuntos relativos à estruturação formal do poema podem, de fato, indicar certa preocupação formalista que nem os modernistas de 1922 (com a liberação da "pesquisa estética”) nem os poetas das gerações seguintes (João Cabral, que veio a elevar essas questões a níveis altos de racionalização, e os poetas da geração 45, cuja preocupação formal restringia-se à reutilização de formas abandonadas pelos modernismos anteriores) chegaram a demonstrar.

Tais considerações já são suficientes para encaminharmos as questões levantadas e isso poderá ser feito, como dissemos anteriormente, a partir de dois ângulos de visão que se sobrepõem: o da perspectiva de uma poética envolvida com a realidade nacional e o do lugar ocupado por ela no contexto do Modernismo brasileiro.

A interdependência entre essas duas perspectivas pode ser compreendida se levarmos em consideração o conhecido tripé que serviu de fundamento para o Modernismo brasileiro na visão de Mário de Andrade, a saber: "[1] o direito 
permanente à pesquisa estética; [2] a atualização da inteligência artística brasileira; [3] e a estabilização de uma consciência criadora nacional” (ANDRADE. In: TELES, 1997, p. 310).

A nosso ver, as vanguardas dos anos 50 e 60 não estiveram desligadas dessa tríplice preocupação e, nesse ponto, foram tão "modernistas" e tão "participantes" quanto os "modernismos" que as precederam. Ocorre que a leitura que as últimas vanguardas fizeram dos "sinais" da modernidade foi diferente, em vários aspectos, da leitura dos primeiros movimentos modernistas e isso, menos do que um fator de distanciamento é, na realidade, uma manifestação do caráter de heterogeneidade que parece ser um ponto pacífico no que diz respeito a qualquer tentativa de caracterização do Modernismo.

Sob a égide dos valores que informam um mundo cada vez mais modificado pelos efeitos das transformações industriais e pelas novas formas de linguagem, tanto a Poesia Concreta quanto a Práxis pensaram e produziram suas obras e teorias. Os dados dessa nova configuração mundial e das novas linguagens foram decisivos para o modo como ambas as vanguardas puseram em exercício tanto suas "pesquisas estéticas" quanto a "atualização da inteligência artística brasileira”. O que causa uma aparência de divórcio entre essas vanguardas e a realidade nacional é o fato de que, para elas, a ideia de um projeto de atuação dentro da realidade não esteve ligada a uma abordagem de elementos considerados específicos da cultura nacional. Isso significa, a nosso ver, menos um desvirtuamento do Modernismo do que uma recolocação dos seus problemas, sob novos aspectos.

No tocante à "pesquisa estética”, concordemos ou não com as propostas dos integrantes do grupo Noigandres, foram eles os responsáveis por um profundo questionamento acerca dos valores da poesia instituída. O sentido da experimentação concretista que é, na verdade, a procura de uma nova poesia baseada em outros padrões de composição, ao mesmo tempo em que exigiu um alto grau de pesquisa estética, significou, também, uma "atualização" da produção brasileira com dados teóricos e artísticos internacionais que ainda não haviam sido considerados, a não ser muito pontualmente, por poetas de gerações anteriores. 
A primeira questão que deve ser proposta àqueles que acusam a Poesia Concreta de dar as costas à realidade nacional é: como seria possível, para uma proposta de poesia que se coloca mais na perspectiva de comunicação de estruturas do que de conteúdos, conciliar os pressupostos que a constituíam com a abordagem mais direta de elementos culturais, antropológicos, sociais, etc.? Em outras palavras, é preciso perceber até que ponto não se estava exigindo do pensamento e da prática concretistas algo que lhes era totalmente estranho. Eis um aspecto. Em seguida (e isto nos parece fundamental), destacamos que o fato de a Poesia Concreta não tratar "temática" ou "conteudisticamente" as várias dimensões da realidade não significa que ela esteja fora do raio de abrangência dessas questões e que o todo de sua produção artística e teórica não seja uma tomada de posição diante delas. Porém, costuma-se contestar a Poesia Concreta partindo-se do pressuposto de uma certa forma de atuação e participação poéticas que, embora tenha garantido os ganhos e aquisições do nosso Modernismo, já não são as mesmas partilhadas pelo grupo concretista. Tal linha de refutação não acata a possibilidade inversa, ou seja, de a vanguarda concretista ter vindo a acrescentar ao Modernismo um novo horizonte de leitura de suas problemáticas fundamentais, pois a preocupação está votada sempre a identificar a "subtração" da Poesia Concreta de um rumo que fora acertado pela Semana de 1922. Por conseguinte, pensando no fio condutor de Vanguarda $e$ subdesenvolvimento, não haveria ali uma certa imposição de uma lógica linear externa aos fatos que compõem a literatura brasileira? Explicando: ao descrever uma sucessão de realizações literárias como enredadas por uma lógica evolutiva subjacente, Gullar estabelece um esquema explicativo, dentro do qual, manifestações como o Concretismo não passariam de inflexões ou retrocessos, jamais contribuições ou acréscimos. Cai-se assim no risco de atribuir uma "razão teleológica” à história da nossa poesia que terminaria por encerrá-la em um modelo explicativo algo castrador e pouco inclusivo.

Dessa forma, não é necessariamente a questão do formalismo que se deve ter em vista se se quer criticar a Poesia Concreta. Se, por formalismo, pretende-se generalizar traços de uma poesia voltada mais para sua estrutura do que para possíveis conteúdos, de fato, o Concretismo é um formalismo. Contudo, a 
equação de que formalismo é igual à alienação parece pouco acertada na medida em que, de um lado, restringe o potencial de criticidade da poesia a um tipo convencionado de abordagem temática e conteudística e, por outro, impede o advento de outras possibilidades de leitura e conserva hábitos de sensibilidade que poderiam ser, se não abandonados, pelo menos enriquecidos a partir de outros procedimentos de fruição, análise e interpretação da obra e de suas relações com o contexto. A Poesia Concreta é, certamente, passível de crítica sob vários aspectos, porém, o que estamos defendendo aqui é que os pressupostos dessas críticas precisam se precaver contra certas totalizações argumentativas, sob pena de: 1) determinar um sentido unificador para o Modernismo, que, pela sua heterogeneidade intrínseca, é, no mínimo, rebelde a conceitualizações definitivas; 2) desconsiderar o fato de que uma solução formalista nem sempre representa uma "fuga" idealista e que tal solução pode ser uma tomada de posição diante dos problemas conjunturais; 3) deixar de lado o possível potencial de criticidade de uma proposta que, ao criar novos valores, põe em xeque certa prática sedimentada sobre uma dada concepção do que seja o sentido do poético.

Com consideráveis ressalvas, parte dessas considerações vale para a Práxis, em vários aspectos, alguns deles já sinalizados ao longo desta discussão. Primeiro é preciso considerar que, não fosse a tomada de posição concretista, a Práxis seria bem diferente do que ela se tornou. Os textos da Instauração mostram isso muito claramente. Sem querer minimizar a originalidade das reflexões de Chamie, é fato que grande parte delas ergueu-se em antagonismo direto com a poética concretista. Dada a proposta deste trabalho, ativemo-nos a enfatizar tal antagonismo no ponto específico da relação dessas vanguardas com a realidade exterior ao poema. Nesse sentido, se o formalismo da Poesia Concreta deve-se ao fato de ser ela uma poesia que abdicou da representação, o mesmo não se pode dizer da Práxis, cujo programa foi totalmente voltado para uma poetização problematizadora dos dados da realidade. No entanto, ainda que tal preocupação tenha sido central, os poemas-práxis possuem, de forma bastante evidente, a marca da experimentação formal. Por essa última característica, a Práxis representou uma forma "equilibrada" de ajustamento entre os atributos de uma vanguarda e o caráter de uma poesia "participante", tal como era entendido o 
termo na época em que, pelas forças das circunstâncias políticas, se cobrava dos movimentos artísticos um comprometimento social, como foi o caso dos concretistas com o "pulo da onça” em 1961. Porém, a solução praxista não pode ser equiparada à chamada poesia "panfletária" ou a qualquer tipo de arte genericamente considerada como "engajada".

O posicionamento de Chamie sobre a relação da Práxis com o Modernismo e com a questão nacional pode ser resumido nos seguintes pontos: de fato coube ao Modernismo todo o mérito da colocação de um nacionalismo artístico brasileiro. No entanto, malgrado todas as rupturas com os academismos das escolas literárias com fortes ranços do complexo colônia-metrópole, cujo sintoma mais manifesto é a cultura da importação de padrões artísticos europeus, o Modernismo não conseguiu constituir-se enquanto um verdadeiro projeto de instauração, tendo sido mais uma atitude de recusa (decerto procedente) do que, efetivamente, uma plataforma de proposições. Além disso, mesmo as grandes produções modernistas ressentem-se, na visão de Chamie, de certa limitação que a abordagem temática impõe aos seus autores. Nesse sentido, um Macunaíma, na "tentativa de organização de uma fala única brasileira não consegue superar a dicção folclórica do tema do 'herói sem nenhum caráter" (CHAMIE, 1974a, p. 111), assim como um Grande sertão: veredas "não vence, ainda, uma constante regional folclórica" (CHAMIE, 1974a, p. 111).

O fundamento central dos argumentos de Mario Chamie é o caráter totalizador e revolucionário da vanguarda em nome da qual ele advoga. Para essa, o Modernismo é uma "situação-limite" que deve ser superada por um projeto de transformação coletiva, cujo escopo último é a formação de uma "consciência de leitura” entre intelectuais e povo:

[...] "a literatura-Práxis se estabelecerá, em definitivo, como fazer histórico, quando intelectuais e povo forem leitores de uma mesma linguagem" [trecho do "manifesto didático"]. Vale dizer: quando houver o domínio pleno de uma consciência de leitura, identificando produtor e consumidor de arte num só projeto. Não significa isto que o escritor deva escrever para o leitor segundo a educação e o alcance intelectual deste, numa sociedade de privilégios (CHAMIE, 1974a, p. 57). 
Nesse ponto do pensamento da Instauração-Práxis, as demonstrações práticas escasseiam, à medida que vai ficando cada vez mais difícil visualizar quais os caminhos de acesso a tal utopia congregante, na medida em que, como reconhece seu próprio fundador, não é possível ao autor "falar diretamente às massas" (CHAMIE, 1974a, p. 78).

Tudo se passa, portanto, como se o Modernismo, caudatário ainda de uma atitude "temática" na literatura, permanecesse limitado pelas peias da "Literaturaliterária”, cuja característica principal é o fato de atuar "paralelamente" ao mundo. Nesse sentido, por mais que a atitude modernista tenha dado saltos qualitativos no que tange a um processo desmistificador da cultura brasileira, sua relação com essa não escapa da eleição temática e ilustrativa dos dados da realidade, permitindo-se, não raro, a apresentação de cenas imbuídas de folclorismos, como no caso das obras mencionadas de Mário de Andrade e Guimarães Rosa.

A crítica de Chamie parece querer demonstrar que toda a problemática nacionalista, dentro de tal quadro, carecerá de uma verdadeira potencialidade transformadora e que só a Práxis possui as condições de assumir uma atitude de verdadeira superação das potencialidades abertas pela Semana de 1922. Parece cabível ilustrar a tomada de posição praxista parafraseando a conhecida frase de Marx: "os filósofos não fizeram mais do que interpretar o mundo de várias maneiras, mas agora trata-se de o transformar" (MARX, ENGELS, 1980, p. 33). No caso da Práxis, poderia ser dito: os poetas não fizeram mais do que tematizar o mundo de várias maneiras, mas agora trata-se de levantá-lo para transformá-lo.

Já tivemos oportunidade de indicar que toda a estruturação formal do Poema Práxis tem em vista a viabilização do seu projeto maior de transformação social. Embora não tenhamos entrado nos detalhes dos aspectos formais, chegamos a assinalar o fato de que tal estruturação corresponde, ao mesmo tempo, ao levantamento de uma prática coletiva e tende a gerar um resultado poético passível de intervenção de leitores co-autores. Mesmo que nos ocupássemos, no momento, em expor os detalhes dessa que é a característica básica do Poema-Práxis, tal esforço seria apenas parcialmente suficiente para demonstrarmos o elo causal entre tal proposta de poesia e os resultados que dela 
seria possível depreendermos. Ou seja, a relação contida entre uma coisa e outra (o poema instaurador e o efeito social) resultaria do fato de que o poema, ao envolver a estrutura e a problemática da área de levantamento, da qual se origina, possibilitaria a convergência entre o autor e o leitor numa mesma "consciência de leitura", isto quando ambos "forem leitores de uma mesma linguagem". Finalmente, podemos notar que a pretensão da Práxis acerca da problemática que discutimos é a de representar o instante histórico de ruptura vanguardista em que literatura e realidade estariam conjugadas, de tal sorte que ambas pertenceriam a uma zona comum, de modo que "poema" e "problema" seriam instantes de uma mesma prática. O nacionalismo sairia, assim, do lugar de temática convencional modernista para dar lugar à constante crítica da questão desenvolvimento/subdesenvolvimento, que estaria no cerne de toda atividade produtora da cultura nacional.

\section{Referências}

AGUILAR, Gonzalo. Poesia concreta brasileira: as vanguardas na encruzilhada modernista. São Paulo: EDUSP, 2005.

BENSE, Max. Pequena estética. Trad. J. Guinsburg e Ingrid Dormien. São Paulo: Perspectiva, 1971.

CAMPOS, Augusto de; CAMPOS. Haroldo de; PIGNATARI, Décio. Teoria da poesia concreta: textos críticos e manifestos 1950-1960. São Paulo: Duas Cidades, 1975.

CHAMIE, Mário. Instauração praxis I. São Paulo, Quíron, 1974a. . A palavra inscrita. Ribeirão Preto: FUNPEC Editora, 2004. Instauração praxis II. São Paulo, Quíron, 1974b. Sábado na hora da escuta. São Paulo: Summus, 1978.

GULLAR, Ferreira. "Vanguarda e subdesenvolvimento". In: Cultura posta em questão/Vanguarda esubdesenvolvimento. Rio de Janeiro: José Olympio, 2002. 
QUEVEDO, Raiael Campos.

"Arte concreta". In: Etapas da arte contemporânea: do cubismo aoneoconcretismo. São Paulo: Nobel, 1985.

MARX, Karl; ENGELS, Friedrich. Sobre literatura e arte. Trad. Olinto Beckerman. São Paulo: Global Editora, 1980.

ORTEGA Y GASSET, José. Desumanização da arte. Trad. Ricardo Araújo. São Paulo: Cortez, 2001.

PIGNATARI, Décio. Informação, linguagem e comunicação. São Paulo: Cultrix, 1991.

TELES, Gilberto Mendonça. Vanguarda europeia e modernismo brasileiro. Apresentação e crítica dos principais movimentos vanguardistas. $17^{\underline{a}}$ ed. Petrópolis: Vozes, 2002.

\footnotetext{
* Doutor em Literatura pela Universidade de Brasília (UnB) e Professor Adjunto do Departamento de Letras da UFMA.
} 